\title{
Isolating Soil-Born Fungi and Determining Their Phytotoxicty Against Weeds in Millet
}

\author{
Naila Azam¹, Ikramullah Khan ${ }^{2 *}$, Muhammad Shuaib ${ }^{3 * *}$, Hameed Alsamadany ${ }^{4}$, \\ Ghazala Shaheen ${ }^{5}$, Farooq Jan ${ }^{2}$, Yahya Alzahrani ${ }^{4}$, Rukhsana Kausar ${ }^{6}$, \\ Muzammil Shah ${ }^{4}$, Sadia Nadir ${ }^{7}$, Saraj Bahadur ${ }^{8}$, K.M. Dawar ${ }^{9}$ \\ ${ }^{1}$ Department of Weed Science, University of Agriculture, Peshawar, Pakistan \\ ${ }^{2}$ Department of Botany, Abdul Wali Khan University, Mardan, Pakistan \\ ${ }^{3}$ School of Ecology and Environmental Science, Yunnan University, Kunming, China \\ ${ }^{4}$ Department of Biological Sciences, King Abdulaziz University, Jeddah, Saudi Arabia \\ ${ }^{5}$ Department of Botany, University of Balochistan, Quetta, Pakistan \\ ${ }^{6}$ Department of Environmental Sciences, International Islamic University, Islamabad, Pakistan \\ ${ }^{7}$ Department of Chemistry, University of Science and Technology, Bannu, Pakistan \\ ${ }^{8}$ College of Life and Pharmaceutical Sciences, Hainan University Haikou, China \\ ${ }^{9}$ Department of Soil and Environmental Sciences, University of Agriculture Peshawar, Pakistan
}

Received: 12 August 2018

Accepted: 6 March 2019

\begin{abstract}
Studies on the isolation of soil-born fungi and their phytotoxicity against weeds and millet were conducted in the Centre of Biotechnology and Microbiology at the University of Peshawar in 2015. For this purpose, soil from the three botanical gardens in Peshawar valley - the Botanical Garden of the Pakistan Forest Institute (PFI), the Islamia College Botanical Garden and the University of Peshawar Botanical Garden in Aza Khel - were collected and analyzed for the identification and isolation of different species of soil-born fungi. A total of seven species of fungi were isolated from the three botanical gardens, 5 species (Alternaria spp., Aspergillus niger, Aspergillus flavus, Penicillium spp., and Rhizopus spp.) from the botanical garden of the Pakistan Forest Institute, 4 species (Fusarium spp., Cladosporium spp., Penicillium spp., and A. flavus) from Islamia College Botanical Garden and 3 species (A. flavus, Alternaria spp and A. niger) from the University of Peshawar botanical garden in Aza Khel. Among these, A. flavous was found in all three botanical gardens with higher frequency such as in PFI (90\%), in Islamia College Botanical Garden (65\%) and the University of Peshawar Botanical Garden in Aza Khel (50\%). This species produces a large number of colonies such as in PFI (56), Islamia College (24) and in the University of Peshawar (7) colonies per petri dish. In the second part of the studies, crude extract of A. flavus was collected and tested on the seed mortality of five different weeds and millet. Those weeds were A. retroflexus, C. album, Sonchus arvensis, Galium aparine and Viola arvensis. Crude extract of A. flavus with different concentrations (i.e., 10, 100 and $1000 \mu \mathrm{g} / \mathrm{mL}$ ) were prepared
\end{abstract}

*e-mail: ikramullah@awkum.edu.pk

**e-mail: zeyadz44@yahoo.com 
and applied on weed seeds kept in the petri dishes. Due to the toxic effect of the extract of A. flavus, all weed seeds were killed, i.e., A. retroflexus (100\%), C. album (100\%), S. arvensis (100\%), G. aparine $(100 \%)$ and $V$. arvensis (100\%). Similarly crude extract of $A$. flavus also killed millet seeds completely (100\%). Therefore, our results suggest that extract of $A$. flavus could be used as a biological control agent for controlling weeds through targeted spray as well as in turf and commercials areas.

Keywords: soil, fungal biodiversity, phytotoxic, millet, botanical gardens, Peshawar Valley

\section{Introduction}

Fungi are a large group of large and small organisms which are placed in Eumycota [1]. They live everywhere in nature, including land, air, and water, and in animals and plants [1]. 1.5 million species of Fungi exist, of which almost 70,000 are known [1]. Fungi are organisms that have the ability to produce different pharmaceutically useful compounds, like penicillin, cyclosporine, and lovastatin [2]. Fungi and its products are used in different products of health improvement [3]. Fungi are also used in drugs and antibiotics [3, 4]. Many species of fungi affect the wild and agricultural biodiversity. However, some species of fungi are used as biological control agents for controlling weeds [5]. Moreover, filamentous fungi are also used in the production of citric acid and other food additives such as soya. Some large fungi such as mushrooms are quite rich in protein and are eaten in different parts of the world [4]. The majority of fungi species produce by-products and secondary metabolites [6]. Secondary metabolites are divided into various groups, including terpenes, indoleterpenes, polyketides, and non-ribosomal peptides [6]. Bioactive products are produced by plants, endophytic fungi and bacteria $[7,8]$. They have a significant role in agriculture, food and the medical industry $[7,8]$.

Penicillic acid is carcinogenic in experimental animals [9]. The potential gene products are present in the genome of the fungus $A$. nidulans, which control the production of metabolites [10]. This suggests the presence of clustered secondary metabolite genes, which have the capability to generate up to 27 polyketides, one terpene, 14 nonribosomal peptides, and two indole alkaloids, also recognizing the potential controller of expression of these clusters [10]. Intercropping systems and crop rotations provide us with better management of soil fungi [11].

Millet is an important source of food and fodder in Pakistan and is grown on 0.548 million hectares with a production of 0.201 million tons and an average of $631 \mathrm{kh} / \mathrm{ha}$. Millet is an important crop growing under environmental conditions that are too harsh for growing other cereal crops to produce a good yield of grains. Those areas are characterized by lower annual rainfall, high temperature and low soil fertility. The yield is very low, which is due to weeds, fungal attack, limited use of improved cultivars, a low level of fertilizer application and low water availability [12]. Among all those factors, weeds significantly decreased the yield of millet [12]. Important weeds of millet are A. retroflexus, $S$. arvensis, V. arvensis, G. aparine and C. album [12]. Therefore, an important aspect of this study will be the identification of suitable fungus that could be used as potential bioherbecides. This study was planned with the following objectives: (1) to isolate and purify the fungal species from the soil of botanical gardens in Peshawar valley, (2) to identify fungal species from the soils of botanical gardens in Peshawar Valley, and (3) to study the phytotoxic effect of fungus against weeds and millet.

\section{Materials and Methods}

\section{Soil Sample Collection}

Soil samples were collected from three sites of the Peshawar valley. Those sites were botanical gardens because botanical gardens are conservation points where soil and plant biodiversity are conserved. Those experiments were conducted with the randomised complete block design (RCBD) having three sites as treatments and each treatment was replicated four times, i.e., four samples were taken from each botanical garden:

i. Botanical Garden, University of Peshawar, Aza Khel.

ii. Botanical Garden, Islamia College University of Peshawar.

iii. Botanical Garden, Pakistan Forest Institute (PFI), University Campus Peshawar.

Soil samples were collected from each botanical garden at four points, which was at least $10 \mathrm{~m}$ away from each other and at a depth of $20 \mathrm{~cm} .100 \mathrm{~g}$ of soil was collected from each site and each point, from which $1 \mathrm{~g}$ of soil was taken and serial dilution was performed.

\section{Potato Dextrose Agar (PDA) Medium}

To prepare the potato dextrose agar (PDA) medium, $200 \mathrm{~g}$ potato was taken, peeled and boiled in $500 \mathrm{~mL}$ distilled water for 30 minutes. The potato paste was taken and raised its volume to $1000 \mathrm{~mL}$ by adding distilled water. Then $200 \mathrm{~mL}$ was taken in a flask and $20 \mathrm{~g}$ sugar and $4 \mathrm{~g}$ agar were added to it. The flask was plugged with cotton and the cotton plug was covered with aluminum foil. The medium was autoclaved at $121^{\circ} \mathrm{C}$ temperature for 15 to 20 minutes at $15 \mathrm{psi}$ pressure. 


\section{Isolation of Fungi}

For isolation of fungi, soil samples were collected from the soil of the botanical garden of Peshawar Valley in clean polythene bags, and samples were transferred to the Microbiology Research Laboratory at the Centre of Biotechnology and Microbiology, University of Peshawar, Pakistan. According to the instructions, potato dextrose agar medium was autoclaved along with the Petri plates wrapped in paper for 15 to 20 minutes at $121^{\circ} \mathrm{C}$ at $15 \mathrm{psi}$ pressure for sterilization of media and petriplates. PDA medium was transferred to a laminar flow hood (LFH) so that it cooled down to $60^{\circ} \mathrm{C}$, and petriplates were kept in an oven at $190^{\circ} \mathrm{C}$ for drying. Petriplates were also shifted to LFH after dryness. 20-22 mL of PDA medium was poured carefully into each petriplate in the LFH. The medium was allowed to solidify, and after solidification petriplates were wrapped with para-film. We put the petriplates in the incubator overnight at $37^{\circ} \mathrm{C}$ to check the sterility.

\section{Serial Dilution}

For isolation of fungi, serial dilution was used, which is one of the most widely used methods. Serial dilution of the soil (Islamia College, University of Peshawar and Pakistan Forest Institute) was performed, for which one gram of soil was taken from each sample and $10 \mathrm{~mL}$ distilled water was added, which was further diluted 10 times. Ten test tubes were taken for each soil sample.

For serial dilution, distilled water was autoclaved at $121^{\circ} \mathrm{C}$ for 15 to 20 minutes at 15 psi in screw-capped test tubes. In the first test tube, $1 \mathrm{gm}$ soil and $10 \mathrm{~mL}$ distilled water were added and the sample was mixed thoroughly. In the other 9 test tubes, $9 \mathrm{~mL}$ distilled water was added. $1 \mathrm{~mL}$ distilled water was taken from the first tube (with $10 \mathrm{ml}$ distilled water and $1 \mathrm{~g}$ soil) and was transferred to the second test tube (with $9 \mathrm{ml}$ distilled water) so that its volume increased to $10 \mathrm{~mL}$. The same was repeated with the remaining test tubes. We put a micropipette in the holder in the test tube so that $1 \mathrm{~mL}$ mixture of distilled water and soil placed in it was then transferred into the Petri dish with PDA media. We spread it on the Petri dish with the help of a sterilized glass spreader. This was similarly done for other petriplates.

The plates were allowed to dry in LFH for 10 minutes and then wrapped with parafilm. All these steps were carried out in LFH. Before doing work in $\mathrm{LFH}$, first on the red and orange light, we swabbed it with ethanol and distilled water. Then we switched off the red and orange lights and turned on the green light (UV) and left the room for 5 to 10 minutes, then turned off the green light and turned on the red and orange lights. All work was done in the LFH near the flame. Plates were then incubated at 27 to $30^{\circ} \mathrm{C}$ for 7 to 10 days. These experiments were repeated several times in order to isolate and purify the fungal strains. After ithe incubation period we saw different fungal colonies grown on petriplates. After isolation and purification, the fungal strains were kept in the refrigerator at $4^{\circ} \mathrm{C}$ for use in the future.

\section{Identifying Fungal Strains}

The experiment was performed for microscopic and morphological identification of isolated fungal strains. Colony morphology, pigmentation, and pure fungal spore structure isolates were studied using a light microscope (100-200 magnification). Fungal strains were identified by studying different traits, i.e., structure of hyphae, colony structure, and arrangement of spores. The coloration of the colonies was also observed by growing the fungal strains on PDA and Czapec dox agar medium. For further confirmation, the isolates were sent for identification to the Department of Plant Pathology at the University of Agriculture in Peshawar.

\section{Biological Activity}

Biological activities such as phytotoxic activity against weeds of millet and millet seeds were conducted step by step. In those steps, we studied the inhibitory effect of fungus on the weeds and seeds of millet.

\section{Phytotoxic Activity on Weeds and Millet}

The experiment was conducted in a Petri dish using completely randomized design (CRD) in four replications. A tissue paper was placed in a Petri dish with 10 seeds of test weed specie, keeping the appropriate distance. Each Petri dish was replicated three times and a control treatment was kept with each concentration. Different dose concentrations (10, $100,1000 \mu \mathrm{g} / \mathrm{mL}$ ) of the fungal (A. flavus) extracts were applied to Petri dishes through a dropper and then water was provided as required each day. The seed germination data was recorded on a daily basis. The whole experimental setup was continued for 18 days. The data was recorded on the mortality (\%) of seeds of different species of weeds. The activity of fungal extract was also checked for the presence of phytotoxics against millets. The same procedure above (CRD method) was adopted for weed species.

\section{Statistical Analysis}

Data analyzed through ANOVA and the CRD method was adopted for the weed species, and SPSS for making graphs. 


\section{Results and Discussion \\ Number of Fungal Species Found in Three Botanical Gardens}

A total of seven species of fungi was collected from the three botanical gardens of Peshawar Valley. There was a variation in the number of species, and a maximum number of fungal species was found in the botanical garden of the Pakistan Forest Institute (Table 1), and a minimum number (i.e., three species) of fungi were collected from the botanical garden of the University of Peshawar (Table 1). The difference could be due to the age of the botanical garden and environmental factors, which affects the number of fungal species in the soil [12]. Moreover, types of vegetation of the botanical garden, latitude, and altitude also affect fungal diversity [13], which is also shown in our data (Table 1). Furthermore, our results are similar to [13], who stated that these diversity patterns indicate that fungal diversity was highest in the forest systems. Therefore, it is concluded from the data (Table 1) that soil fungal communities are dependent on the type of vegetation.

\section{Types of Fungi Found in Botanical Gardens}

In the Pakistan Forest institute garden, five species were identified, while in the Islamia College garden four species of fungi were identified and isolated (Table 1). However, at the University of Peshawar garden only three species of fungi were identified and isolated. Among them, A. flavus was common in all three gardens, which shows that A. flavus is common in the soil of Peshawar Valley (Table 1). Our results are similar to those of [14], who stated that A. flavus is common in soil and on decaying organic matter, which is available in all three botanical gardens.

On the other hand, Fusarium spp and Cladosporium spp were found in the Islamia College garden only, while Penicillium spp was shared with the Pakistan Forest Institute garden (Table 1). However, Rhizopus spp was found only in the Pakistan Forest Institute and was absent from the other two gardens (Table 1).

The highest number of fungi in the Pakistan Forest Institute garden could be due to favorable conditions, i.e., a large number of trees, adequate moisture, temperature, and organic substrates [15]. While few types of fungal species in the University of Peshawar could be due to the non-favorable environment such as salinity, which is prevailing in the University of Peshawar garden, which could adversely affect fungal flora $[14,16]$.

\section{Frequency of Fungi in the Soil of the PFI Botanical Garden}

When the frequency of fungi in the PFI was compared statistically, significant differences were found and $A$. flavus were found with the highest frequency

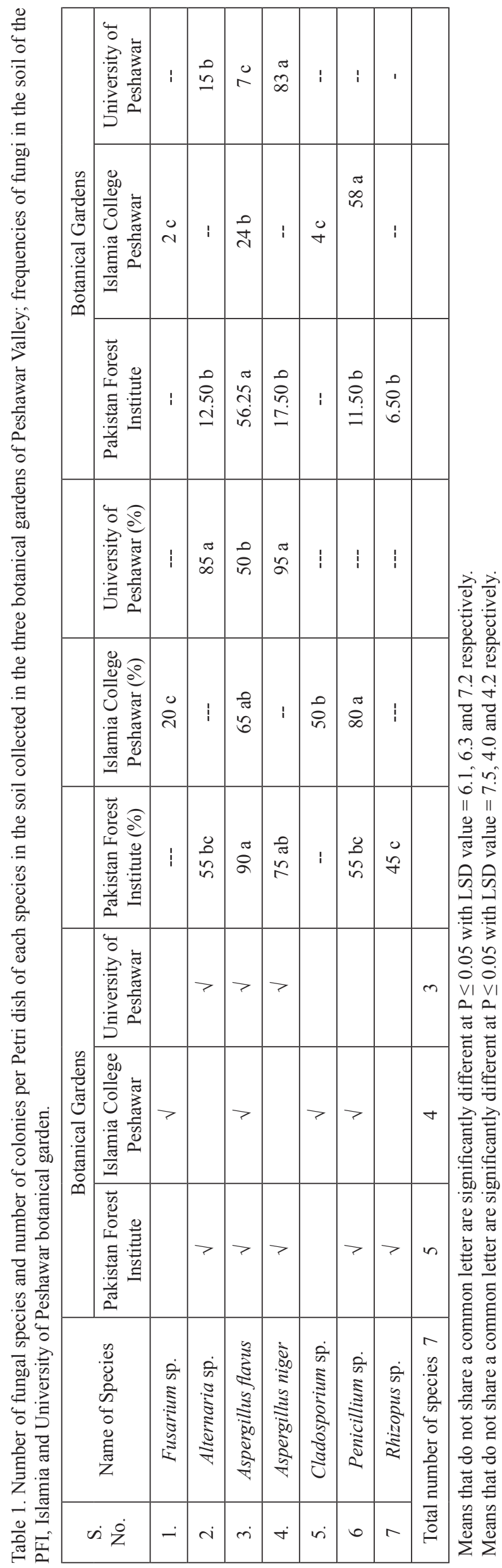


(90\%), while Penicillium spp was found with the lowest frequency $(55 \%)$, which is equal to the frequency of Alternaria spp (Table 2). The second highest fungal species was $A$. niger, which is comparable with A. flavus (Table 2). These findings support the arguments of [14], who stated that A. flavous are frequently found in the soil and on decaying organic matter.

\section{Frequency of Fungus in the Soil of the Islamia College Garden}

When the frequency of fungi in the Islamia College garden was analyzed and compared statistically, significant differences were found and Penicillium sp. was found at the highest frequency (80\%), while Fusarium sp. was found at the lowest frequency (20\%; Table 1). The second highest fungal species was A. flavus, which is comparable with Penicillium sp. (Table 1). This could be due to the soil factor of the Islamia College garden, which is clayey and loamy, and the decaying organic matter is available for fungal growth $[16,17]$.

\section{Frequency of Fungus in the Soil of the Peshawar University Garden}

When the frequency of fungi in the Peshawar University garden was statistically analyzed and compared, significant difference was found and A. niger was found at the highest frequency (95\%), which is on par with Alternaria sp. (Table 1). While A. flavus was found at the lowest frequency (50\%; Table 1). This could be due to the soil salinity factor of the Peshawar University garden, where the soil is saline and could significantly decrease the frequency of fungi in the soil [18].

\section{Number of Colonies per Petri Dish in PFI Garden Soil}

When the number of colonies of each fungus was statistically analyzed, a significant difference was also found in the number of colonies of the five fungi collected from the soil of the PFI garden (Table 1). The highest numbers of colonies were found in A. flavus, which is significantly different from all other fungi (Table 2). Our results showed that there is a rapid growth of A. flavus in the favourable conditions of the botanical garden, which is similar to the results obtained by [14, 19]. However, Ahmad et al. [19] reported that Aspergillus sp. shows the fastest growth among other fungal species, and in a few minutes it produces a few hundred colonies in favorable conditions.

\section{Number of Colonies per Petri Dish in Islamia College Soil}

When the number of colonies of each fungus was statistically analyzed and compared using Tukey test, significant difference was also found in the number of colonies of the three fungi collected from the soil of Islamia College (Table 1). The highest numbers of colonies were found in Penicillium spp, which is significantly different from all other fungi, while the lowest number of colonies was found in Fusarium spp (Table 1). Our results showed that along with the frequency of Penicillium spp, its growth is also rapid and dominant among all the fungal species collected from the Islamia College garden (Table 1), which is corroborated with the results obtained by [13].

\section{Number of Colonies per Petri Dish in Peshawar University Soil}

When the number of colonies of each fungus was statistically analyzed and compared using Tukey test, a significant difference was also found in the number of colonies of the three fungi collected from the Peshawar University soil (Table 1). Highest numbers of colonies were found in $A$. niger, which is significantly different from all other fungi, while the lowest number of colonies was found in (Table 1). This could be due to the soil salinity factor of the Peshawar University garden, where the soil is saline and could significantly decrease the growth of fungi in the soil [18].

\section{Phytotoxic Activity}

\section{Extract of Aspergillus Flavus Against Weed Seeds}

A total of seven species of fungi was isolated from the soils of three botanical gardens. Among those, which was common in all the three botanical gardens was selected. The crude extract of A. flavus was tested against five weed and millet seeds. Results are disused below.

\section{Effect of Extract of Aspergillus flavus on Seed Mortality of Amaranthus retroflexus}

Phytotoxic activity of the crude metabolites of A. flavus was tested against $A$. retroflexus, and seed mortality (\%) is shown (Fig. 1). A total of three dose

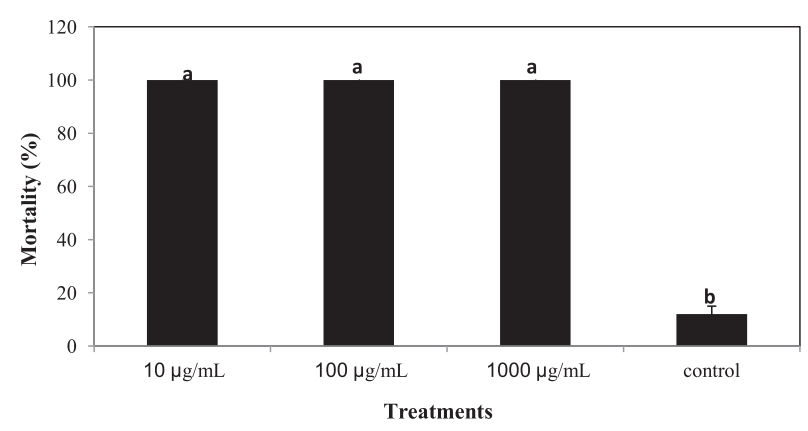

Fig. 1. Effect of crude metabolites of Aspergillus flavus on mortality of seeds of Amaranthus retroflexus. 


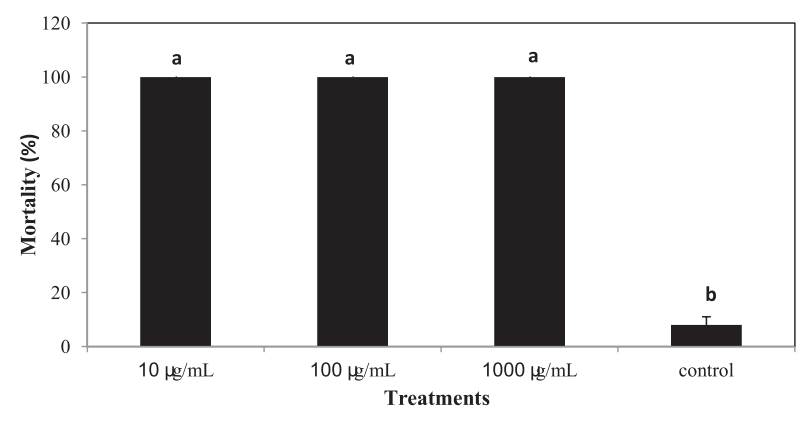

Fig. 2. Effect of crude metabolites of Aspergillus flavus on mortality of seeds of Chenopodium album.

concentrations of 10,100 and $1000 \mu \mathrm{g} / \mathrm{mL}$ were used to measure phytotoxicity of the metabolites. When the percentage of the mortality seeds of $A$. retroflexus under different doses (i.e., 10, 100 and $1000 \mu \mathrm{g} / \mathrm{mL}$ ) were statistically analyzed and compared with the control, significant differences were shown in Fig. 1. 100\% mortality of $A$. retroflexus seeds were found in all three treatments (Fig. 1). Therefore, our results are similar to those of [20], who reported that fungus infection could significantly reduce or inhibit the germination of seeds. Therefore, this could be used as a biological control agent for controlling weeds in crops.

\section{Effect of Extract of Aspergillus flavus on Seed Mortality of Chenopodium album}

Phytotoxic activity of the crude metabolites of A. flavus was tested against C. album and seed mortality (\%) shown (Fig. 2). A total of three dose concentrations of 10,100 and $1000 \mu \mathrm{g} / \mathrm{mL}$ were used to measure the phytotoxicity of the metabolites. When the percentage of the mortality seeds of C. album under different doses $(10,100$ and $1000 \mu \mathrm{g} / \mathrm{mL})$ were statistically analyzed and compared with the control, a significant difference was shown (Fig. 2). $100 \%$ the mortality of C. album seeds was found in all three treatments (Fig. 2). Therefore, our results are similar to those of Tehranchian et al. [20] and Clyde et al. [21], who reported that fungus infection could significantly reduce or inhibit the germination of seeds. Therefore, this could be used as a biological control agent for controlling weeds in crops.

\section{Effect of Extract of Aspergillus flavus on Seed Mortality of Sonchus arvensis}

Phytotoxic activity of the crude metabolites of A. flavus was tested against $S$. arvensis and the seed mortality (\%) shown (Fig. 3). A total of three dose concentrations of 10,100 and $1000 \mu \mathrm{g} / \mathrm{mL}$ were used to measure the phytotoxicity of the metabolites. When the percentage of the mortality seeds of $S$. arvensis under different doses $(10,100$ and $1000 \mu \mathrm{g} / \mathrm{mL})$ were statistically analyzed and compared with the control, a significant difference was shown (Fig. 3). 100\%

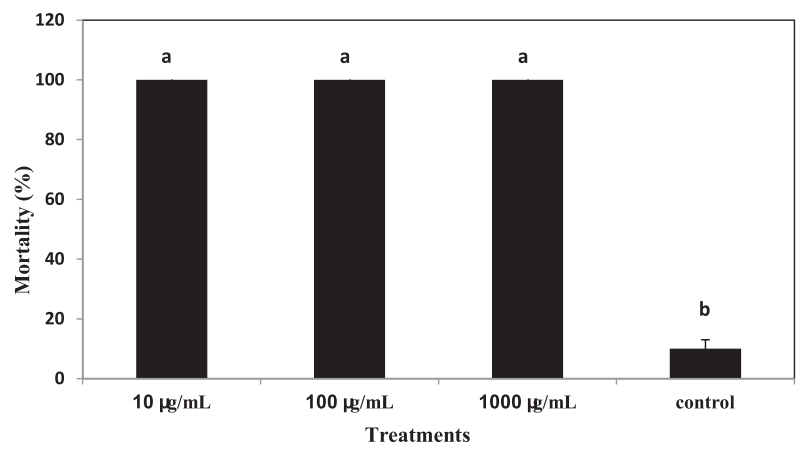

Fig. 3. Effect of crude metabolites of Aspergillus flavus on mortality of seeds of Sonchus arvensis.

mortality of $S$. arvensis seeds was found in all three treatments (Fig. 3). Therefore, our results are similar to those of Tehranchian et al. [20] and Clyde et al. [21], who reported that fungus infection could significantly reduce or inhibit the germination of seeds. Therefore, this could be used as a biological control agent for controlling weeds in crops. Our results are also similar to Hassan and Ayres [22], who stated that fungal isolates or extracts are useful for the control of weeds and kill weeds in the field.

\section{Effect of Extract of Aspergillus flavus on Seed Mortality of Galium aparine}

Phytotoxic activity of the crude metabolites of A. flavus was tested against $G$. aparine and the seed mortality (\%) shown (Fig. 4). A total of three dose concentrations of 10,100 and $1000 \mu \mathrm{g} / \mathrm{mL}$ were used to measure the phytotoxicity of the metabolites. When the percentage of the mortality seeds of $G$. aparine under the three different doses were statistically analyzed and compared with the control, a significant difference was shown (Fig. 4). 100\% mortality of $S$. arvensis seeds were found in all three treatments (Fig. 4). Our results are also similar to those of Hassan and Ayres [22], who stated that fungal isolate extracts are useful for the control of weeds and kill weeds in the field.

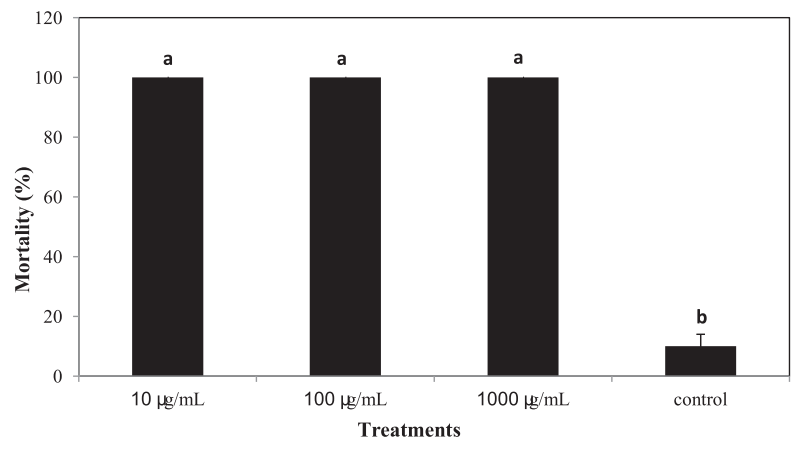

Fig. 4. Effect of crude metabolites of Aspergillus flavus on mortality of seeds of Galium aparine. 


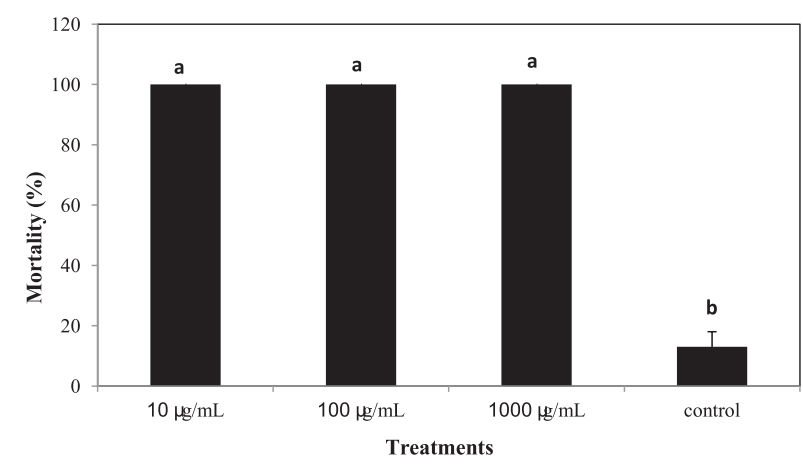

Fig. 5. Effect of crude metabolites of Aspergillus flavus on mortality of seeds of Viola arvensis.

\section{Effect of Extract of Aspergillus flavus on Seed Mortality of Viola arvensis}

Phytotoxic activity of the crude metabolites of A. flavus was tested against $V$. arvensis and the seed mortality (\%) shown (Fig. 5). A total of three dose concentrations of 10,100 and $1000 \mu \mathrm{g} / \mathrm{mL}$ were used to measure the phytotoxicity of the metabolites. When the percentage of the mortality seeds of $V$. arvensis under the three different doses were statistically analyzed and compared with the control, a significant difference was shown (Fig. 4). 100\% mortality of S. arvensis seeds were found in all three treatments (Fig. 5). Our results are also similar to those of Kandulaa et al. [23], who stated that fungi significantly reduced or stopped weed germination.

\section{Effect of Extract of Aspergillus flavus on Seed Mortality of Millet Seeds}

Phytotoxic activity of the crude metabolites of A. flavus was tested against millet seeds and the seed mortality (\%) shown (Fig. 6). A total of three dose concentrations of 10,100 and $1000 \mu \mathrm{g} / \mathrm{mL}$ were used to measure the phytotoxicity of the metabolites. When the percentage of the mortality seeds of millet seeds under

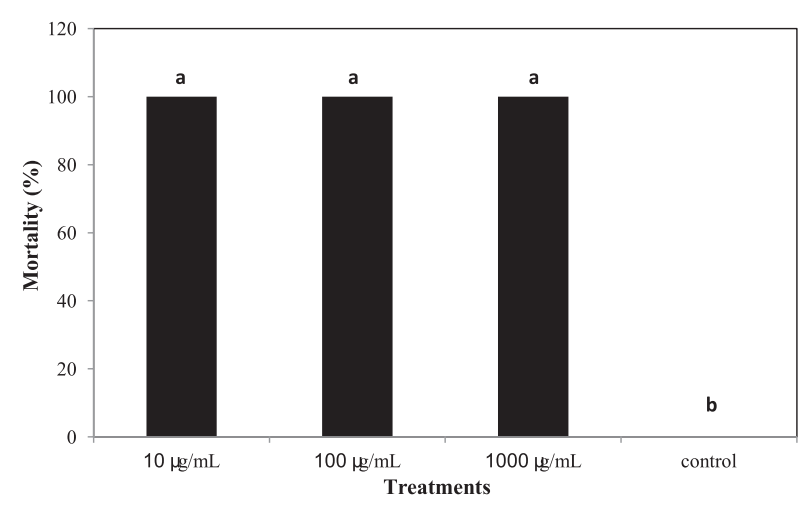

Fig. 6. Effect of crude metabolites of Aspergillus flavus on mortality of seeds of millet. the three different doses were statistically analyzed and compared with the control, a significant difference was shown (Fig. 6). 100\% mortality of Sonchus arvensis seeds was found in all three treatments (Fig. 6). Our results are also similar to those of Kandulaa et al. [23], who stated that fungi significantly reduced or stopped the germination of seeds. This is one of the side effects of the applications of fungus on seeds of millet because it also completely inhibits the growth of millet seeds. Therefore, we can use the fungal extracts on weeds directly, not mixed with the crop.

Studies on isolation and identification of soil-born fungal flora from three botanical gardens in Peshawar Valley and their phytotoxicity against weeds and millet were conducted in the Centre of Biotechnology and Microbiology at the University of Peshawar in 2015. Soil samples were collected from the Botanical Garden of the Pakistan Forest Institute (PFI), the Islamia College Botanical Garden and the University of Peshawar Botanical Garden at Aza Khel, and analysed for identification in the laboratory of the Centre of Biotechnology and Microbiology at the University of Peshawar. In the first step, serial dilution was done in the laboratory. Media used for the fungal growth are PDA and CYA. Different colour fungus colonies were grown in Petri dishes and then purified the fungal colonies. We checked whether the fungus was active or not by using the nutrient agar media and nutrient broth. Secondary metabolites were obtained in CYA media. The isolated spores were transferred to the CYA media and incubated for 10-20 days on shaking at $150 \mathrm{rpm}$ at $28^{\circ} \mathrm{C}$. After incubation, $40 \%$ concentrated HCL was added to each flask to acidify the culture medium, then ground with a blender and filtered with filtered paper. Then equal volume of ethyl acetate was added and mixed well by shaking about 20 to 30 minutes. Metabolites were concentrated by rotary evaporator. Crude extract was obtained and subjected to phytotoxic activity of weeds and millet. A total of seven species of fungi were isolated from the three botanical gardens, 5 species (Alternaria spp., A. niger, A. flavus, Penicillium spp. and Rhizopus spp.) from the Pakistan Forest Institute, 4 species (Fusarium spp., Cladosporium spp., Penicillium spp., and A. flavus) from Islamia College and 3 species (A. flavus, Alternaria spp and A. niger) from the University of Peshawar. Among those, A. flavus was found in all three gardens with higher frequency such as in PFI (90\%), in Islamia College $(65 \%)$ and at the University of Peshawar (50\%). This species produces a large number of colonies such as in PFI (56), in Islamia College (24) and the University of Peshawar (7) colonies per Petri dish. In the second part of the studies, crude extract of A. flavus was collected and tested on the seed mortality of five different weeds and millet: A. retroflexus, $C$. album, S. arvensis, $G$. aparine and $V$. arvensis. Crude extract of $A$. flavus with different concentrations (10, 100 and $1000 \mu \mathrm{g} / \mathrm{mL})$ were prepared and applied on weed seeds kept in Petri dishes. Due to the toxic effect of the extract of A. flavus, all 
weed seeds were killed: A. retroflexus (100\%), C. album $(100 \%)$, S. arvensis $(100 \%)$, G. aparine $(100 \%)$ and $V$. arvensis (100\%). Similarly, crude extract of A. flavus also killed millet seeds completely (100\%). Therefore, our results suggest that extract of A. flavus could be used as a biological control agent for controlling weeds through targeted spray as well as in turf and commercial areas.

\section{Conclusions}

Seven species of fungi were isolated from the soil of three botanical gardens of Peshawar Valley. A. flavus was found to be common in all three botanical gardens. Extracts of A. flavus were found to be very phytotoxic against weeds of millet, which completely inhibited their seed germination. Based on our results the following recommendations were made: extract of A. flavus could be used a potential herbicide for weeds control, and A. flavus could also be used as a potential biological control agent against weeds.

\section{Acknowlegements}

The authors gratefully acknowledge the support received from the Department of Weed Science at the University of Agriculture in Peshawar, Pakistan. This research work received no specific grant from any donor agency in the public, commercial, or nonprofit sectors, and these organizations have had no involvement in the analysis and interpretation of data, in the writing of the draft, or in the decision to submit the article for publication.

\section{Conflict of Interest}

All authors declare no conflict of interest.

\section{References}

1. GEOFFREY T. Exploitation of fungal secondary metabolites old and new. Microbiology today 27, 118, 2012.

2. KELLER N.P., TURNER G., W BENNETT J. Nat. Rev. Microbiol. 937, 2005.

3. LESSE B., PETER K., BUSK N., MORTEN GRELL., YUHONG H., METTE L., TORE L., PILGAARD., DORIS R., XIAOXUE T. The importance of fungi and of mycology for a global development of bioeconomy. I. M. A. Fungus. 3, 87, 2012.

4. DOOLITTLE R.F., FENG D.F., TSANG S., CHO G., LITTLE E. Determining divergence times of the major kingdoms of living organisms with a protein clock. Science. 271, 470, 2014.

5. HALL R.A., PAPIEROK B. Fungi as biological control agents of arthropods of agricultural and medical importance. Parasitology. 84, 205, 2009.
6. ELLEN M.F., BARBARA H. Secondary metabolism, regulation and role in fungal biology. Curr.Opin.Microbiol. 11, 481, 2008.

7. JOHN M.U., KROHN., FLORKE H., AUST J., DRAEGER S., SCHULZ B. Biologically active secondary metabolites from fungi. Oidiolactones A-F, labdanediterpenederavatives isolated from Oidiodendron truncate. J. Nat. Prod. 62, 1218, 2015.

8. STROBEL G.A., MILLER R.V., MARTINEZ-MILLER C., CONDRON M.M., TEPLOW D.B., HESS W.M. Cryptocandin a potent and antimycotic from the endophytic fungus Cryptosporiopsis cf. quercina. Microbiology. 145, 1919, 1999.

9. DICKENS F., JONES H. E. Carcinogenic activity of a series of reactive lactones and related substances. Br. J. Cancer. 15, 85, 1961.

10. BOK J.W., HOFFMEISTER D., MAGGIO-HALL L.A., MURILLO R., GLASNER J.D., KELLER N.P. Genomic mining for Aspergillus natural products. Chem Biol. 13, 31, 2016.

11. KIÆR L.P., SKOVGAARD I.M., OSTERGÅRD H. Grain yield increase in cereal variety mixtures. A meta-analysis of field trials.Field Crops Research. 114, 361, 2013.

12. LAPTIEV A.B., DOLZHENKO V. I. Protection of millet crops against weeds. Russian Agricultural Science. 39 (3), 249, 2013.

13. SHI L.L., PETER E. MORTIMER., FERRY SLIK J.W., XIAO M.Z., JIANCHU X.U., WEN T.F., QIAO L.U. Variation in forest soil fungal diversity along a latitudinal gradient. 64, 305, 2014.

14. TOURNAS V.H. Spoilage of vegetable crops by bacteria and fungi and related health hazards. Crit. Rev. Microbiol. 31, 33, 2015.

15. ISAAC S., FRANKLAND J.C., WATLING R., WHALLEY A.J.S. Aspects of Tropical Mycology. Micromycetes. 2, 1, 2014.

16. ANDERSON I.C., CAIMEY J.W.G. Diversity and ecology of soil fungal communities increased understanding through the application of molecular techniques. Environmental Microbiology. 6, 769, 2004.

17. GRIFFIN D.M. Soil moisture and ecology of soil fungi. Biological reviews. 38, 141, 1963.

18. HUANG J., LU C., QIAN X., HUANG Y., ZHENG Z., SHEN Y. Effect of salinity on the growth, biological activity and secondary metabolites of some marine fungi. Act Oeanologica Sinica. 30, 118, 2011.

19. AHMED J., HOSSIAN K.S, BASHAR M.A. Aeromycoflora of Dhaka university campus. Bangladesh J. of Botany. 42, 273, 2013.

20. TEHRANCHIAN P., ADAIR R.J., LAWRIE A.C. Potential for biological control of the weed Angled Onion (Allium triquetrum) by the fungus Stromatinia cepivora in Australia. 43, 381, 2014.

21. CLYDE D., ROBERT E., STETINA C., BOYETTE, HOAGLAND., KENNETH. Biological Control of the Weed Hemp Sesbania (Sesbania exaltata) in Rice (Oryza sativa) by the Fungus Myrothecium verrucaria Agronomy. 4, 74, 2014.

22. HASSAN S., AYRES P.G. The Control of Weeds Through Fungi: Principles and Prospects. The New Phytologist. 115, 201, 1990.

23. KANDULAA D.R.W., JONESB E.E., STEWARTA A., MCLEANA K.L., HAMPTONA. J.G. Trichoderma species for biocontrol of soil-borne plant pathogens of pasture species. 2015. 